\title{
Genetic evaluation for persistency of lactation in Holstein cows using a random regression model
}

\author{
Jaime Araujo Cobuci ${ }^{1}$, Ricardo Frederico Euclydes ${ }^{2}$, Claudio Napolis Costa ${ }^{3}$, Robledo de Almeida Torres ${ }^{2}$, \\ Paulo Sávio Lopes ${ }^{2}$ and Carmen Silva Pereira ${ }^{2}$ \\ ${ }^{I}$ Departamento de Zootecnia, Universidade Federal do Rio Grande do Sul, Porto Alegre, RS, Brazil. \\ ${ }^{2}$ Departamento de Zootecnia, Universidade Federal de Viçosa, Viçosa, MG, Brazil. \\ ${ }^{3}$ Embrapa Gado de Leite, Juiz de Fora, MG, Brazil.
}

\begin{abstract}
A model for analyzing test day records including both fixed and random coefficients was applied to the genetic evaluation of first lactation data for Holstein cows. Data comprising 87045 test-day milk yield records from calving between 1997 and 2001 from Holstein herds in 10 regions of the Brazilian state of Minas Gerais. Six persistency of lactation measures were evaluated using breeding values obtained by random regression analyses. The Wilmink function was used to model the additive genetic and permanent environmental effects. Residual variance was constant throughout lactation. Ranking for animals did not change among criteria for persistency measurements, but ranking changes were observed when the estimated breeding value (EBV) for persistency of lactation was contrasted with those estimated for 305-day milk yield (305MY). The rank correlation estimates for persistency of lactation and 305MY were practically the same for sire and cows, and ranged from -0.45 to 0.69 . The EBVs for milk yield during lactation for sires producing daughters with superior 305MY indicate genetic differences between sires regarding their ability to transmit desirable persistency of lactation traits. This suggests that selection for total lactation milk yield does not identify sires or cows that are genetically superior in regard to persistency of lactation. Genetic evaluation for persistency of lactation is important for improving the efficiency of the milk production capacity of Holstein cows.
\end{abstract}

Key words: genetic evaluation, persistency of lactation, rank correlation, random regression models.

Received: October 11, 2005; Accepted: September 19, 2006.

\section{Introduction}

Milk production traits have traditionally held the leading position as regards selection goals but in dairy cattle breeding the emphasis is gradually shifting from increasing volume to improving the efficiency of production. Increasing attention has also been paid to other traits that are helpful for improving the management of dairy herds and for increasing the efficiency of breeding schemes. Functional traits must also be considered in selection, because these traits have a direct impact on total economic merit (Groen et al., 1997).

The recent recognition of the importance of functional traits in cattle and the possible role of such traits in avoiding deterioration and possibly improving functional traits during breeding has stimulated research in many

Send correspondence to Jaime Araujo Cobuci. Departamento de Zootecnia, Universidade Federal do Rio Grande do Sul, Av. Bento Gonçalves 7712, Bairro Agronomia, 91540-000 Porto Alegre, RS, Brazil. E-mail: jaime.cobuci@ufrgs.br or jcobuci@universiabrasil. net. countries (Interbull, 1999). For example, in the European Union increased milk production is not economically advantageous due to the existing quota system (Gengler, 1996; Tekerli et al., 2000). Although most of the incomes of European breeders are generally derived from the sale of milk, they realize that single trait selection for milk yield will not necessarily yield for them the optimal genetic response in overall economic merit and profit potential. Therefore, there is a demand for the genetic evaluation of other traits to aid in selection decisions. Breeders try, among other measures, to reduce the costs of production by improving persistency of lactation (Tekerli et al., 2000).

Persistency of lactation can be defined as the ability of a cow to maintain milk production after peak yield, with cows being persistent if they tend to maintain their peak yield within a lactation period. Improved persistency of lactation can contribute to reducing the cost of the production system because lactation persistency is associated with feeding and health costs, reproductive performance, resistance to disease and the return from milk considering a 305-day production cycle (Sölkner and Fuchs, 1987; 
Dekkers et al., 1996, 1998). It may be desirable to select for increased persistency without increasing peak yield, the latter subjecting the cow to undesirable stress, health and fertility problems (Kruip et al., 1996).

Although the notion of persistency of lactation yield seems clear, definitions are inconsistent (Grossman et al., 1999) and no consensus has yet been reached. Definitions based on the ratio between milk yields at different stages of lactation or on differences between milk yields at test-days during lactation are arbitrary and do not unique characterize persistency because such parameters are not invariant with respect to the time period chosen (Rekaya et al., 2001).

Several measurements of persistency have been proposed (Sölkner and Fuchs, 1987; Jaromzik et al., 1997; Jakobsen et al., 2002; Cobuci et al., 2004) but the procedure most widely used today to measure lactation persistency is based on the byproduct of the random regression test day model. These models have been extensively applied to the evaluation of milk production traits since they allow a more precise assessment of the environmental effects acting on these traits. The use of the random regression test day model not only improves the accuracy of genetic evaluations but can also evaluate persistency because the estimated breeding value (EBV) for various parts of the lactation can be calculated (Jamrozik et al., 1997).

In this study we evaluated six different measures for describing persistency of lactation in Holstein cows in order to assess the most suitable of these measures for use in random regression test-day models for the genetic evaluation of persistency of lactation.

\section{Material and Methods}

Data consisted of 160,038 test-day milk yield records from Holstein cows calving between 1997 and 2001 in herds supervised by the Milk Recording Service of the Holstein Association of Minas Gerais State (ACGH-MG), in southeastern Brazil.

Data were edited for test-day records between 6 and 305 days in milk (DIM) of first parity cows and calving between 18 and 48 months of age. After applying these criteria 87,045 records from 11,023 first lactation cows, daughters of 936 sires in 251 herds from Minas Gerais State were available for analyses.

We defined four age at calving classes (20 to 24, 25 to 29,30 to 34 and 35 to 48 months) and four calving seasons (January through March, April through June, July through September and October through December) and combined them to produce 16 age-season classes. Cows in the same herd, year and month of milk recording defined the contemporary group fixed effect. The model used for test-day milk yield was:

$y_{i j k l}=H Y M_{i}+\sum_{m=1}^{3} \beta_{k m} Z_{j l m}+\sum_{m=1}^{3} a_{j m} Z_{j l m}+\sum_{m=1}^{3} p_{j m} Z_{j l m}+e_{i j k l}$,

where $y_{i j k l}$ is record $l$ of cow $j$ made on the $\mathrm{t}^{\text {th }}$ days in milk of the first lactation for a cow belonging to subclass $k$ for age-season of calving, $H Y M_{i}$ is the fixed effect of herdyear-month of test $i ; \beta_{k m}$ is the fixed regression coefficient of test-day milk yield as a function of DIM, which describes the shape of the lactation curve within the age-season subclasses; $a_{j m}$ and $p_{j m}$ are random regression coefficients that describe the genetic and permanent environmental effects on each animal, respectively; $e_{i j k l}$ is the random residual effect associated with $y_{i j k l} ; Z_{j l m}$ is the covariable matrices represented by the Wilmink function in which $Z_{j 1 m}=\left(Z_{j 11} Z_{j 12}\right.$ $\left.Z_{j 13}\right)^{\prime}=(1 \mathrm{t} \mathrm{DEX})^{\prime}$, and DEX $=e^{-0,05 . t}, t$ and $m=$ days in milk after calving and the $\mathrm{m}^{\text {th }}$ parameter of the function, respectively.

The Wilmink function (1987) used to model genetic and permanent environmental effects is represented by

$y=a_{1}+a_{2}^{t}+a_{3} e^{-0,05 t}$, for $\mathrm{t}=$ days in milk.

It was assumed that

$$
\left(\begin{array}{l}
\mathbf{a} \\
\mathbf{p} \\
\mathbf{e}
\end{array}\right) \sim \mathrm{N}(0, \mathbf{V}) \text { with, } \mathbf{V}=\left(\begin{array}{ccc}
\mathbf{G} \otimes \mathbf{A} & 0 & 0 \\
0 & \mathbf{P} \otimes \mathbf{A} & 0 \\
0 & 0 & \mathbf{R}
\end{array}\right)
$$

where $\mathbf{G}$ is the genetic covariance matrix of the random regression coefficients, assumed to be the same for all cows; $\mathbf{A}$ is the additive genetic relationship matrix among animals; $\otimes$ is the Kronecker product operator; $\mathbf{P}$ is the permanent environment covariance matrix of the random regression coefficients, assumed to be the same for all cows; $\mathbf{R}=\mathbf{I} \sigma_{e}^{2}$, for $\mathbf{I}$ an identity matrix, and $\sigma_{e}^{2}$ the residual variance assumed to be constant throughout the lactation.

The solutions for the additive genetic random regression coefficients of animal $j$ are represented as $\hat{a}_{j}^{\prime}=\left(\hat{a}_{1 j} \hat{a}_{2 j} \hat{a}_{3 j}\right)$. The estimated breeding value (EBV) of animal $j$ in the $t^{\text {th }}$ DIM is obtained by

$$
E B V_{t j}=\left(\hat{a}_{1 j}+\hat{a}_{2 j} t+\hat{a}_{3 j} e^{-0.05 t}\right)=z^{\prime} t \hat{a} j,
$$

and the estimated breeding value for 305-day milk yield ( $\left.E B V_{305 \mathrm{MY}}\right)$ of animal $j$ is obtained by the sum of the EBV of each $t^{\text {th }}$ DIM.

$$
E B V_{350 \mathrm{MY}}=\sum_{t=6}^{305} E B V_{t} .
$$

Six different measures of persistency of lactation $\left(\mathrm{PS}_{\mathrm{i}}\right)$ based on EBVs for test-days milk yield in different lactation periods were evaluated as follows:

$$
\begin{aligned}
& \mathrm{PS}_{1}=\left(E B V_{280}-E B V_{60}\right) \\
& \mathrm{PS}_{2}=\left(\sum_{t=106}^{205} E B V_{t}-\sum_{t=6}^{105} E B V_{t}\right) \\
& \mathrm{PS}_{3}=\left(\sum_{t=206}^{305} E B V_{t}-\sum_{t=6}^{105} E B V_{t}\right)
\end{aligned}
$$




$$
\begin{aligned}
& \mathrm{PS}_{4}=\sum_{61}^{280}\left(E B V_{t}-E B V_{60}\right) \\
& \mathrm{PS}_{5}=\sum_{60}^{279}\left(E B V_{t}-E B V_{280}\right) \\
& \mathrm{PS}_{6}=\left(E B V_{290}-E B V_{90}\right) .
\end{aligned}
$$

According to these expressions low values of $\mathrm{PS}_{1}$ (Jamrozik et al., 1997), $\mathrm{PS}_{2}$ (Jakobsen et al., 2002), $\mathrm{PS}_{3}$ (Jakobsen et al., 2002), $\mathrm{PS}_{4}$ (Jamrozik et al. (1997) and $\mathrm{PS}_{6}$ (Cobuci et al., 2004) indicate high persistency of lactation, which is the case for a high value of $\mathrm{PS}_{5}$ (Jakobsen et al., 2002).

The solutions for random regression coefficients for each animal were obtained by the restricted maximum likelihood method using the expectation maximization algorithm (EM) of the REMLF90 program (Misztal, 2001). The convergence criterion was $10^{-9}$.

\section{Results and Discussion}

The average, standard deviation (SD) and range of the EBVs for each measure of persistency, 305-d milk yield (305MY) and random regression coefficients of the 936 sires included in the analyses are given in Table 1 . The averages and SD of the EBVs for the measurements of persistency increased from $\mathrm{PS}_{2}$ to $\mathrm{PS}_{5}$. The average EBV was negative for PS5, which showed a similar SD to PS4 and reflects the way that the EBVs were measured. Overall, similar magnitudes in the range of the EBVs were observed for the $\mathrm{PS}_{2}, \mathrm{PS}_{3}, \mathrm{PS}_{4}$ and $\mathrm{PS}_{5}$ persistency measures. This similarity might be have been due to the fact that the measures were calculated based on EBVs for milk yield during different lactation periods. In contrast, the $\mathrm{PS}_{1}$ and $\mathrm{PS}_{6}$ measures were estimated based on the differences between the EBVs for milk yield on two test-days during the lactation, with $\mathrm{PS}_{6}$ differing from $\mathrm{PS}_{1}$ by assuming that the peak yield

Table 1 - Mean \pm standard deviation (SD) and range of estimated breeding values for persistency of lactation $\left(\mathrm{PS}_{1}\right.$ to $\left.\mathrm{PS}_{6}\right), 305$-day milk yield (305MY) and random regression genetic coefficients $\left(a_{1}, a_{2}\right.$ and $\left.a_{3}\right)$ of the Wilmink function for the sires of a population of Holstein cows.

\begin{tabular}{lcc}
\hline Traits & Mean $\pm \mathrm{SD}$ & Range \\
\hline $\mathrm{PS}_{1}$ & $0.023 \pm 0.966$ & 5.442 to -3.769 \\
$\mathrm{PS}_{2}$ & $1.668 \pm 49.394$ & 266.236 to -171.807 \\
$\mathrm{PS}_{3}$ & $2.636 \pm 90.885$ & 510.386 to -316.105 \\
$\mathrm{PS}_{4}$ & $2.812 \pm 107.756$ & 607.975 to -405.214 \\
$\mathrm{PS}_{5}$ & $-2.390 \pm 106.200$ & 427.723 to -594.687 \\
$\mathrm{PS}_{6}$ & $0.019 \pm 0.874$ & 4.896 to -3.512 \\
$305 \mathrm{MY}$ & $11.117 \pm 352.342$ & 1378.87 to -1376.33 \\
$a_{1}$ & $0.024 \pm 1.101$ & 4.965 to -4.652 \\
$a_{2}$ & $9.0 \times 10^{-5} \pm 0.004$ & 0.024 to -0.017 \\
$a_{3}$ & $-0.047 \pm 1.395$ & 7.388 to -7.841 \\
\hline
\end{tabular}

of Holstein cows under tropical conditions is reached after 60 days of lactation.

Substantial variation in the magnitude of the genetic random regression coefficients of the Wilmink function for milk yield was observed among sires, indicating the possible presence of genetic variation in the shape of the lactation curves of sires and daughters. The $a_{1}$ coefficient corresponds to the initial milk production, the $a_{2}$ coefficient expresses the rate of decline in milk production after peak yield and the $a_{3}$ coefficient represents the rate of increase in milk production gain until peak yield. The estimates of the genetic random regression coefficients for the top ten sires with more than 25 daughters ranked for milk yield are given in Tables 2.

The EBVs for the $305 \mathrm{MY}$ of the top ten sires with more than 25 daughters and their corresponding EBVs for each measure of persistency of lactation are given in Table 3 , from which it can be seen that there are differences in the ranking of sires regarding the persistency measures and milk yield. Rank correlation between sire and cows EBVs for persistency and 305MY are given in Table 4. Correlations between EBVs for persistency of lactation were larger than 0.89 for both sires and cows suggesting that, in general, the different measures of persistency evaluated in this study provided similar ranking. However, correlation as low as 0.89 might indicate serious re-ranking for the top animals. The $\mathrm{PS}_{5}$ and $\mathrm{PS}_{6}$ measures of persistency were recommended by Cobuci et al. (2004) for the genetic evaluation of cattle because these measures showed weaker genetic correlations $(-0.31$ and 0.31$)$ with $305 \mathrm{MY}$. The rank correlation between EBVs of sires for these two measures of persistency was -0.99. The dispersal of EBVs of sires with more than 25 daughters ranked for $\mathrm{PS}_{5}$ and $\mathrm{PS}_{6}$ follows a straight line, indicating that, with very few exceptions, the two measures of persistency rank sires equally (Figure 1).

Rank correlation estimates between persistency of lactation and 305MY differed among persistency measure-

Table 2 - Estimates of the genetic random regression coefficients $\left(a_{1}, a_{2}\right.$ and $a_{3}$ ) of the Wilmink function for the top ten sires with more than 25 daughters ranked for milk yield.

\begin{tabular}{lccc}
\hline Sire & $a_{1}$ & $a_{2}$ & $a_{3}$ \\
\hline SM1 & 3.2181 & 0.0102 & -4.1076 \\
SM2 & 2.9362 & 0.0108 & -1.4718 \\
SM3 & 3.4052 & 0.0075 & -3.6204 \\
SM4 & 3.4355 & 0.0059 & -3.4652 \\
SM5 & 1.6257 & 0.0136 & -2.4346 \\
SM6 & 3.2191 & 0.0083 & -4.4048 \\
SM7 & 3.4386 & 0.0043 & -3.7200 \\
SM8 & 1.8657 & 0.0138 & -3.7007 \\
SM9 & 2.3752 & 0.0078 & -4.1336 \\
SM10 & -0.4027 & 0.0244 & -1.4838 \\
\hline
\end{tabular}


Table 3 - Estimated breeding values for different measures of persistency of lactation ( $\mathrm{PS}_{1}$ to $\left.\mathrm{PS}_{6}\right)$ and 305-day milk yield (305MY) for the top ten sires with more than 25 daughters ranked for milk yield.

\begin{tabular}{lccccccc}
\hline Sire & $\mathrm{PS}_{1}$ & $\mathrm{PS}_{2}$ & $\mathrm{PS}_{3}$ & $\mathrm{PS}_{4}$ & $\mathrm{PS}_{5}$ & $\mathrm{PS}_{6}$ & $305 \mathrm{MY}$ \\
\hline SM1 & 2.45 & 163.56 & 265.97 & 288.97 & -252.15 & 2.08 & 1378.87 \\
SM2 & 2.45 & 130.06 & 238.21 & 277.24 & -264.05 & 2.17 & 1362.32 \\
SM3 & 1.83 & 129.26 & 204.62 & 218.46 & -186.02 & 1.54 & 1316.44 \\
SM4 & 1.47 & 110.93 & 170.28 & 178.02 & -146.97 & 1.22 & 1253.25 \\
SM5 & 3.11 & 172.49 & 308.73 & 354.92 & -333.10 & 2.75 & 1085.17 \\
SM6 & 1.45 & 86.40 & 148.56 & 166.97 & -152.38 & 1.26 & 905.09 \\
SM7 & 1.79 & 94.96 & 174.07 & 202.68 & -193.14 & 1.59 & 887.14 \\
SM8 & -2.21 & -24.42 & -137.82 & -217.46 & 271.03 & -2.21 & 866.83 \\
SM9 & 1.26 & 68.59 & 123.68 & 142.76 & -134.63 & 1.11 & 856.99 \\
SM10 & -1.17 & -4.22 & -65.83 & -112.2 & 146.79 & -1.20 & 854.48 \\
\hline
\end{tabular}

Table 4 - Rank correlation between estimated breeding values for different measures of persistency of lactation $\left(\mathrm{PS}_{1}\right.$ to $\left.\mathrm{PS}_{6}\right)$, 305-day milk yield (305MY) and random regression genetic coefficients $\left(a_{1}, a_{2}\right.$ and $\left.a_{3}\right)$ of sires (upper diagonal) and cows (lower diagonal)

\begin{tabular}{lcccccccccc}
\hline Traits & $\mathrm{PS}_{1}$ & $\mathrm{PS}_{2}$ & $\mathrm{PS}_{3}$ & $\mathrm{PS}_{4}$ & $\mathrm{PS}_{5}$ & $\mathrm{PS}_{6}$ & $305 \mathrm{MY}$ & $a_{1}$ & $a_{2}$ & $a_{3}$ \\
\hline $\mathrm{PS}_{1}$ & & 0.92 & 0.98 & 0.99 & -0.99 & 0.99 & 0.49 & -0.00 & 0.99 & -0.18 \\
$\mathrm{PS}_{2}$ & 0.93 & & 0.97 & 0.94 & -0.89 & 0.89 & 0.69 & 0.25 & 0.88 & -0.48 \\
$\mathrm{PS}_{3}$ & 0.98 & 0.97 & & 0.99 & -0.96 & 0.96 & 0.59 & 0.11 & 0.96 & -0.32 \\
$\mathrm{PS}_{4}$ & 0.99 & 0.95 & 0.99 & & -0.98 & 0.98 & 0.53 & 0.04 & 0.98 & -0.23 \\
$\mathrm{PS}_{5}$ & -0.99 & -0.90 & -0.97 & -0.99 & & -0.99 & -0.45 & 0.05 & -0.99 & 0.13 \\
$\mathrm{PS}_{6}$ & 0.99 & 0.90 & 0.97 & 0.99 & -0.99 & & 0.45 & -0.05 & 0.99 & -0.13 \\
$305 \mathrm{MY}$ & 0.50 & 0.69 & 0.59 & 0.53 & -0.46 & 0.46 & & 0.81 & 0.44 & -0.71 \\
$a_{1}$ & -0.03 & 0.23 & 0.08 & 0.01 & 0.07 & -0.07 & 0.81 & & -0.06 & -0.76 \\
$a_{2}$ & 0.99 & 0.90 & 0.97 & 0.99 & -0.99 & 0.99 & 0.45 & -0.08 & & -0.11 \\
$a_{3}$ & -0.09 & -0.42 & -0.23 & -0.14 & 0.04 & -0.04 & -0.65 & -0.75 & -0.02 & \\
\hline
\end{tabular}

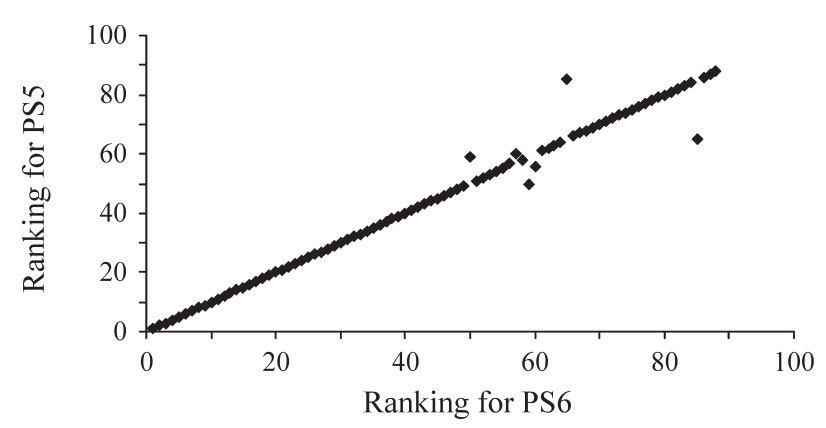

Figure 1 - Dispersal in ranking of sires with more than 25 daughters for the PS5 and PS6 measurements of persistency of lactation.

ments and were dependent on the way persistency was defined (Table 4). The lowest rank correlation estimates between persistency of lactation and 305MY were obtained for $\mathrm{PS}_{5}$ and $\mathrm{PS}_{6}$, for both sires (-0.46 and 0.46) and cows (-0.45 and 0.45), and, as expected, agree with the results of Cobuci et al. (2004). These estimates demonstrate the weak association between production and persistency of lactation; thus, cows with the same milk production may present different levels of persistency of lactation (Gengler, 1996; Jamrozik et al., 1998; Van Der Linde et al., 2000). These estimates also indicate that animals with larger EBVs for persistency of lactation are not exactly the same as those with larger EBVs for 305MY.

Except for $\mathrm{PS}_{2}$, the rank correlation estimates between persistency and the genetic random regression coefficient $a_{2}$ for sires and cows were close to unity, confirming that $a_{2}$ is also a measure of persistency of lactation. Rank correlation between $a_{2}$ and MY305 was 0.45 , the same value obtained for the estimates between MY305 and $\mathrm{PS}_{5}$ and $\mathrm{PS}_{6}$.

The dispersal in ranking of 88 sires with more than 25 daughters is shown in Figure 2 for $305 \mathrm{MY}$ and $\mathrm{PS}_{5}$ and Figure 3 for $305 \mathrm{MY}$ and $\mathrm{PS}_{6}$, the best sires for $305 \mathrm{MY}$ and persistency being shown in the lower left corner of these figures. The top five sires for $305 \mathrm{MY}$ ranked $82,83,72,70$ and 87 for $\mathrm{PS}_{6}$ while, in contrast, the top five sires for PS6 ranked $62,40,61,88$ and 8 for $305 \mathrm{MY}$.

The percentage of sires or cows in common according to increasing levels of selection for persistency of lactation and 305MY are given in Figure 4 for sires and Figure 5 for 
cows. At high selection intensities $(<10 \%)$ there are few animals in common but, as expected, the percentage increases as the percentage of animals selected for 305MY increases. There were no significant differences between the PS1, PS3, PS4, PS5 and PS6 measurements, while the PS2 measurement showed the lowest percentages of animals in common.

The EBVs for milk yield across lactation for the top five sires for high $305 \mathrm{MY}$ with more than 25 daughters are shown in Figure 6. The EBV curves indicate genetic differences between the best top five sires selected for the milk yield. Similarly, the EBVs for milk yield across lactation of the top five sires ranked for $\mathrm{PS}_{6}$ are given in Figure 7, which also shows the genetic differences between sires in terms of the persistency of lactation of their daughters. Thus, comparison between the EBVs of sires for persistency or milk yield across lactation (Figures 6 and 7) reveals that the curves differ for sires with higher EBV for $305 \mathrm{MY}$ or $\mathrm{PS}_{6}$, confirming the weak association between $305 \mathrm{MY}$ and persistency of lactation. Additionally, the top five sires (SM1 to SM5) for 305MY ranked respectively $82,83,72,70$ and 87 for $\mathrm{PS}_{6}$ while, in contrast, the top five sires (SP1 to SP5) for PS6 ranked 62, 40, 61, 88 and 8 for 305MY.

The trends in estimated breeding values of sires and cows across lactation according to the year of birth of the cows is shown in Figure 8, from which it can be seen that there is a clear difference in average EBVs across the years. In the earlier years the curves are flat, and differences become clear (particularly after early lactation) in the last

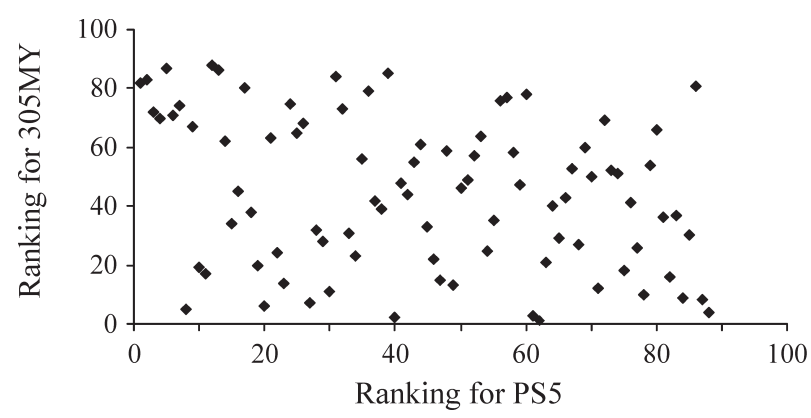

Figure 2 - Dispersal in ranking of sires with more than 25 daughters for 305-day milk yield (305MY) and persistency of lactation $\left(\mathrm{PS}_{5}\right)$.

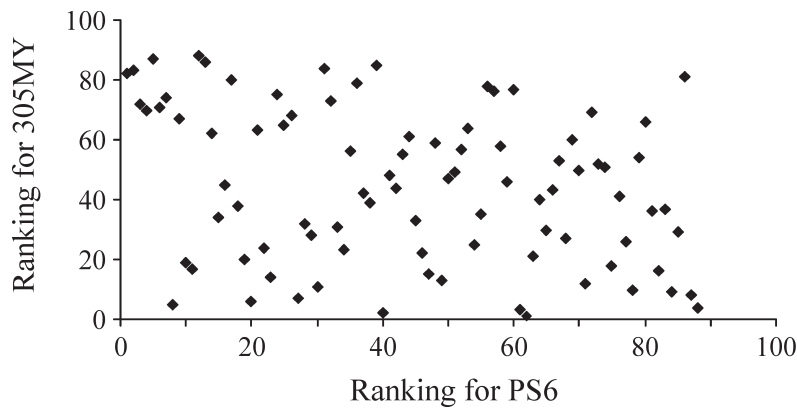

Figure 3 - Dispersal in ranking of sires with more than 25 daughters for 305-day milk yield (305MY) and persistency of lactation $\left(\mathrm{PS}_{6}\right)$. three years, indicating a positive trend regarding improved 305MY. Average EBVs of sires for persistency of lactation and 305-day milk yield according to the birth year of cows is shown Table 5 . Figure 9 clearly demonstrates a positive trend for milk yield, but no significant trend in average EBVs of sires for persistency in the 1993-1999 period.

Overall, these results indicate that an increase in $305 \mathrm{MY}$ may not lead to improvement in the level of persistency of lactation unless selection for $305 \mathrm{MY}$ also takes

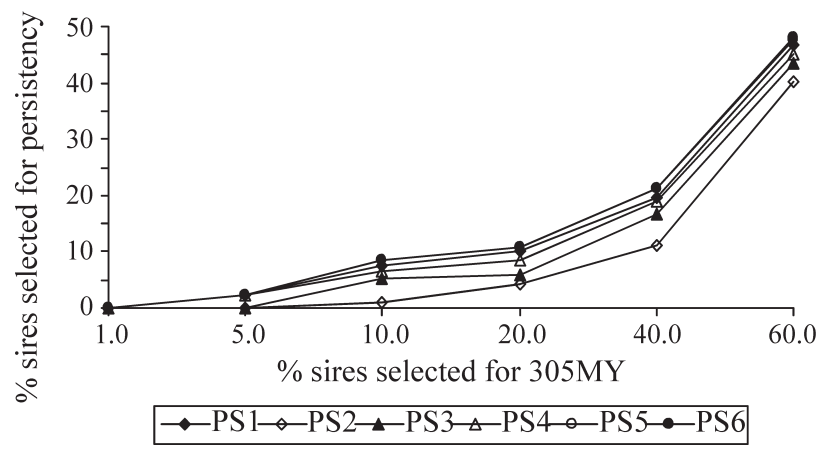

Figure 4 - Percentage of sires selected for persistency of lactation (PS 1 -PS6) when selecting for 305-day milk yield (305MY), at different selection intensities.

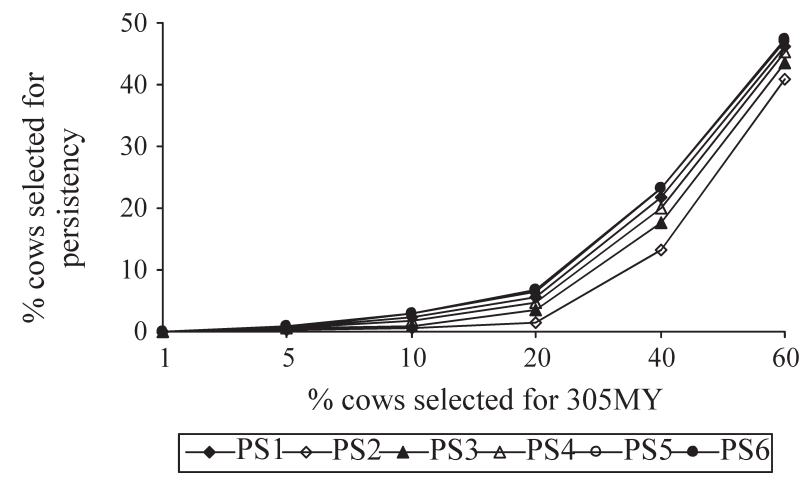

Figure 5 - Percentage of cows selected for persistency of lactation (PS 1 -PS6) when selecting for 305-day milk yield (305MY), at different selection intensities.

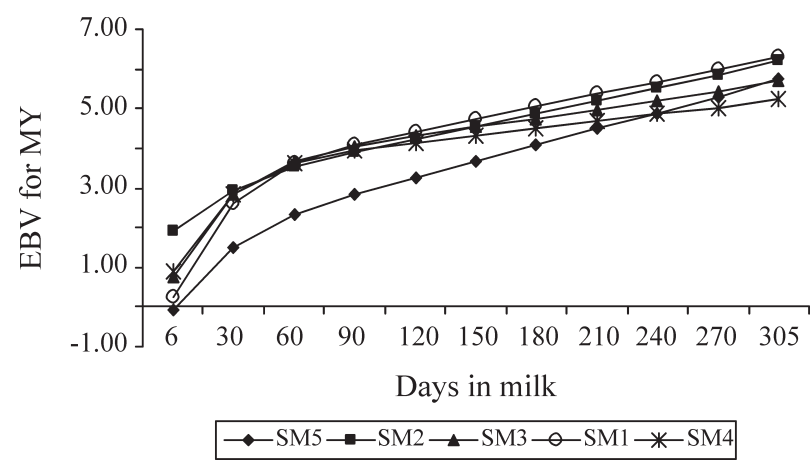

Figure 6 - Estimated breeding values across lactation of the top five sires (SM1-SM5) with more than 25 daughters ranked for 305-day milk yield (305MY). 
into account the selection of animals that show higher levels of persistency of lactation. An increase in 305MY might be obtained by the selection of animals that show higher levels of persistency of lactation, which means select cows with a reduced rate of decline in daily milk yield after peak lactation. Previous studies have investigated the effectiveness of different measures of persistency as selection criteria in improvement of persistency of lactation and milk yield simultaneously (Togashi and Lin, 2004) but other studies have introduced doubts regarding whether the

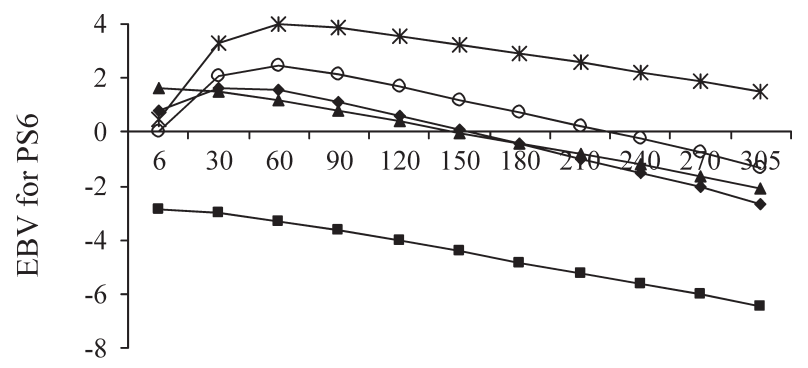

Days in milk

$\multimap \mathrm{SP} 1 \rightarrow-\mathrm{SP} 4 \multimap \mathrm{SP} 3 \multimap \mathrm{SP} 2 \rightarrow \mathrm{SP} 5$

Figure 7 - Estimated breeding values across lactation of the top five sires (SP1-SP5) with more than 25 daughters ranked for persistency of lactation $\left(\mathrm{PS}_{6}\right)$.

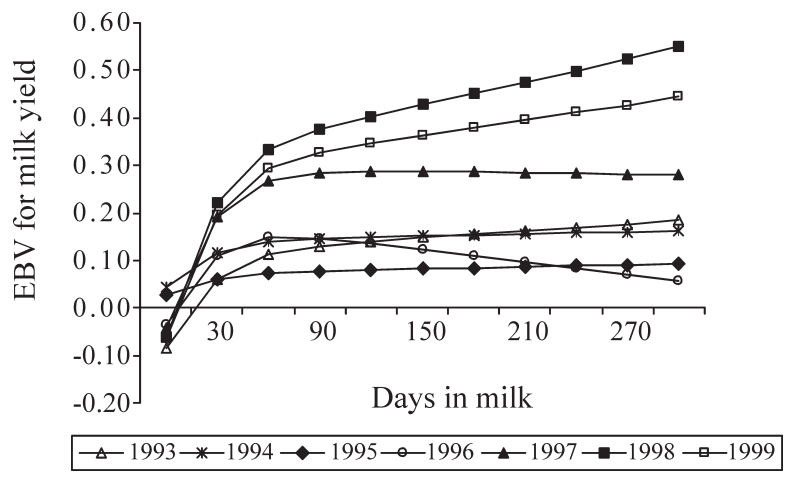

Figure 8 - Average estimated breeding values for milk yield across lactation of cows and sires according to the birth year of cows.

Table 5 - Average estimated breeding values of sires for persistency of lactation $\left(\mathrm{PS}_{1}\right.$ to $\left.\mathrm{PS}_{6}\right)$ and 305-day milk yield (305MY) according to the birth year of cows.

\begin{tabular}{lccccccc}
\hline \multirow{2}{*}{ Traits } & \multicolumn{7}{c}{ Year } \\
\cline { 2 - 8 } & 1993 & 1994 & 1995 & 1996 & 1997 & 1998 & 1999 \\
\hline $\mathrm{PS}_{1}$ & 0.03 & 0.003 & 0.008 & -0.04 & 0.01 & 0.15 & 0.10 \\
$\mathrm{PS}_{2}$ & 3.15 & 0.91 & 0.62 & 0.05 & 4.33 & 11.49 & 9.13 \\
$\mathrm{PS}_{3}$ & 4.58 & 0.94 & 0.99 & -2.54 & 4.18 & 17.53 & 12.97 \\
$\mathrm{PS}_{4}$ & 4.60 & 0.65 & 1.06 & -4.58 & 2.58 & 18.24 & 12.80 \\
$\mathrm{PS}_{5}$ & -3.57 & -0.12 & -0.91 & 6.18 & 0.10 & 14.96 & -9.61 \\
$\mathrm{PS}_{6}$ & 0.03 & 0.001 & 0.07 & -0.05 & -0.00 & 0.12 & 0.08 \\
$305 \mathrm{MY}$ & 21.94 & 20.38 & 10.48 & 19.01 & 52.65 & 87.09 & 78.43 \\
\hline
\end{tabular}

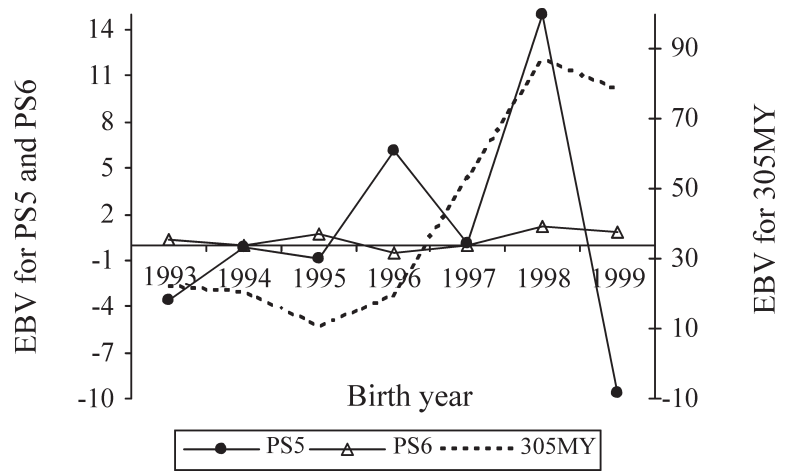

Figure 9 - Average estimated breeding values for 305-day milk yield and persistency of lactation of sires according to the birth year of cows.

days-open effect (Stanton et al., 1992; Dedková and Nemcová, 2003) or does not effect (Van der Linde et al., 2000) the shape of the lactation curve.

Additional research is still needed to identify alternative models to fit test-day data. A Canadian study by Kistemaker (2003) has indicated that test-day models using Legendre polynomials allow for more variability than models using the Wilmink curve. Orthogonal polynomials are most appropriate for the covariates in the random regression model (Schaeffer, 2004), while Jakobsen et al. (2002) has reported that a four-order Legendre polynomial best fitted the data for persistency of milk yield.

Our results confirmed the weak association between $305 \mathrm{MY}$ and persistency of lactation. From the six measures of persistency evaluated in this study, the performance of PS5 and PS6 were very similar and emerged as the most appropriate when applied to describe persistency or milk yield of the Holstein breed in Minas Gerais State, and are thus potential criteria for use in the genetic evaluation of persistency. However, further studies are needed to evaluate other functions for their ability to model the lactation curve and the effectiveness of measures of persistency as selection criteria for the simultaneous improvement of lactation milk yield and lactation persistency.

\section{Acknowledgments}

The authors thank Professor Ignacy Misztal, University of Georgia, USA, for allowing the use of the REMLF90 program.

\section{References}

Cobuci JA, Euclydes RF, Costa CN, Lopes PS, Torres RA and Perreira CS (2004) Análises da persistência na lactação de vacas da raça Holandesa, usando produção no dia do controle e modelo de regressão aleatória. Brazilian Journal of Animal Science 33:546-554 (Abstract in English).

Dedková E and Nemcová E (2003) Factors affecting the shape of lactation curves of Holstein cows in the Czech Republic. Czech Journal Animal Science 48:395-402. 
Dekkers JCM, Jamrozik J, Ten Hag JH, Schaeffer LR and Weersink A (1996) Genetic and economic evaluation of persistency in dairy cattle. Interbull Bulletin 12:97-102.

Dekkers JCM, Tem Hag JH and Weersink A (1998) Economic aspects of persistency of lactation in dairy cattle. Livestock Production Science 53:237-252.

Gengler N (1996) Persistency of lactation yields: A review. Interbull Bulletin 12:97-102.

Groen AF, Torstein S, Colleau JJ, Pedersen J, Pribyl J and Reinsch N (1997) Economic value in dairy cattle breeding with special reference to functional traits. Livestock Production Science 49:1-21.

Grossman M, Hartz SM and Koops WP (1999) Persistency of lactation yield: A novel approach. Journal of Dairy Science $82: 2192-2197$.

Interbull (2000) National Genetic Evaluation programmes for Dairy Production Traits Practiced in Interbull Member Countries 1999-2000. Interbull Bulletin v. 24, Interbull, Uppsala, 111 pp.

Jakobsen JH, Madsen P, Jensen J, Pedersen J, Christensen LG and Sorensen DA (2002). Genetic parameters for milk production and persistency for Danish Holstein estimated in random regression models using REML. Journal of Dairy Science 85:1607-1616.

Jamrozik J, Jansen G, Schaeffer LR and Liu Z (1998) Analysis of persistency of lactation calculated from a random regression test day model. Interbull Bulletin 17:64-69.

Jamrozik J, Schaeffe LR and Dekkers JCM (1997) Genetic evaluation of dairy cattle using test day yields and random regression model. Journal of Dairy Science 80:1217-1226.

Kistemaker GJ (2003) The Canadian test day models using Legendre Polynomials. Interbull Bulletin 31:202-204.

Kruip TAM, Van Der Welf JHJ and Wensing T (1996) Energy balance in early lactation of high producing dairy cows and its relation to reproduction, health and welfare. European Association for Animal Production 84:45-57.

Misztal I (2004) REMLF90 manual: Available at: http://nce.ads. uga.edu/ ignacy/numpub/blupf90/winbin/. Accessed Nov 21, 2004.

Rekaya R, Weigel KA and Gianola D (2001) Hierarchical nonlinear model for persistency of milk yield in the first three lactation of Holsteins. Livestock Production Science 68:181-187.

Schaeffer LR (2004) Application of random regression models in animal breeding. Livestock Production Science 86:35-45.

Sölkner J and Fuchs W (1987) A comparison of different measures of persistency with special respect to variation of test-day milk yields. Livestock Production Science 16:305319.

Stanton TL, Jones LR, Everett RW and Kachman SD (1992) Estimating milk, fat, and protein lactation curves with a test day model. Journal of Dairy Science 75:1691-1700.

Tekerli M, Akinci Z, Dogan I and Akcan A (2000) Factors affecting the shape of lactation curves of Holstein cows from the Balikesir Province of Turkey. Journal of Dairy Science 83:1381-1386.

Van Der Linde R, Groen A and Jong G (2000) Estimation of genetic parameters for persistency of milk production in dairy cattle. Interbull Bulletin 25:113-116.

Togashi K and Lin CY (2004) Efficiency of different selection criteria for persistency and lactation milk yield. Livestock Production Science 87:1528-1535.

Wilmink JBM (1987) Adjustment of test-day milk, fat and protein yields for age, season and stage of lactation. Livestock Production Science 16:335-348.

Associate Editor: Pedro Franklin Barbosa 